\title{
THE ACCURACY OF FORMULAS USED TO ASSESS STRENGTH LOSS DUE TO DECAY IN TREES
}

\section{By Brian C.P. Kane ${ }^{1}$ and H. Dennis P. Ryan III ${ }^{2}$}

\begin{abstract}
There are four formulas that arborists in the United States often use to assess the probability of tree failure. Although they are commonly referred to as "strength loss formulas," three of the formulas (Wagener 1963; Coder 1989; Smiley and Fraedrich 1992) actually estimate the loss in stem moment of inertia $\left(I_{\text {STEM }}\right)$ to evaluate the probability of failure. The formulas estimate the loss in $I_{\text {STEM }}$ by modeling the stem and decay cross-sectional areas as concentric circles. For many trees with decay, however, neither the stem nor the decay cross-sectional areas resemble concentric circles, which may limit the formulas' accuracy. The fourth formula (Mattheck and Breloer 1998) is based on the buckling strength of a cylinder; it also offers a measure of the probability of stem failure. To test how well the formulas estimate the loss in $I_{\text {STEM }}$, we compared each formula's estimates for loss in $I_{\text {STEM }}$ to the actual loss in $I_{\text {STFM }}$ that we calculated using the parallel axis theorem, an engineering technique. Although the parallel axis theorem provides the actual loss in $I_{\text {STEM }}$, it cannot be used in practice because an image of the tree's cross-section is needed to apply it. Significant differences existed between two formulas' (Wagener 1963; Coder 1989) estimates of loss in $I_{\text {STEM }}$ and the actual value. Each of the formulas misclassified some trees as to whether they exceeded the formula's action threshold. When we calculated the actual loss in $I_{\text {STEM }}$ for those trees, however, it was less than 33\%. We present representative stem cross-sections for which the formulas did not accurately represent loss in $I_{\text {STEM }}$.
\end{abstract}

Key Words. Tree hazard; tree risk assessment; stem moment of inertia; decay; mechanical stress.

Arborists and urban foresters often assess the risk of tree failure, and through experience and research, have developed guidelines to improve the assessment procedure. Annually, however, tree failures continue, damaging property, injuring people, and leading to costly insurance claims and, sometimes, litigation. Therefore, it is vital that arborists continue to refine risk assessment, incorporating new research data in the procedure. One tool in tree risk assessment is the use of formulas to estimate stem strength loss due to decay, which, in turn, estimates the probability of stem failure. The formulas, which are based solely on the cross-sectional geometry of the tree stem and decay area, are based on engineering beam mechanics and had been previously tested only with ex post facto studies and observation (Kane et al. 2001). Considering the large number of variables that affect tree failure and the risk of damage that can result from failure, a reevaluation of the formulas seemed appropriate.
The formulas model the tree as a cantilevered beam and look at the cross-sectional geometry of the stem (beam), including decay, to estimate the probability of failure. To determine the probability of failure of a beam using a static engineering analysis, one needs three pieces of information: (1) the force acting on the beam, (2) the beam's crosssectional geometry, and (3) the beam's material properties [i.e., the material's breaking strength, or modulus of rupture (MOR)]. The first two pieces of information can then be used with the following equation, which an engineer uses to calculate bending stress in a beam:

$$
\sigma=\frac{-M^{*} y}{I}
$$

where $(\sigma)$ is bending stress (a measure of force per unit area), (M) represents the applied force or bending moment, $(y)$ is the distance from the neutral axis of bending to the edge of the beam (Figure 1), and (I) is the moment of inertia of the beam. The moment of inertia of any beam (including a tree stem) is based only on the geometry of the beam's cross-section and essentially measures the beam's resistance to bending. From Equation 1, it is clear that the stress calculation does not depend on the beam's material properties. Material properties are still important, however, as the following example illustrates. Consider two trees, a red oak (Quercus rubra L.) and a white willow (Salix alba L.) with the same dbh. If the same force acts on each tree, the stress each tree endures is the same by Equation 1. Because the oak wood is stronger (i.e., has a greater MOR) than the willow wood, the willow cannot endure as much stress as, and thus will fail before, the oak.

Because of the way I is calculated (see Appendix 1), as tree diameter increases, the moment of inertia of the stem $\left(I_{\text {STEM }}\right)$ increases exponentially. In other words, a $4 \mathrm{~cm}(1.6$ in.) diameter stem has a moment of inertia (i.e., resists bending) four times greater than a $2 \mathrm{~cm}$ ( $0.8 \mathrm{in}$.) diameter stem, even though the diameter is only twice as large. Another consequence of the way I is calculated is that the outer wood fibers of the stem contribute exponentially more to $I_{\text {STEM }}$ than the inner wood fibers. Furthermore, unless the stem cross-section is symmetrical, the direction in which a force acts on the tree will also affect $I_{\text {STEM }}$. We can use the analogy of bending a wooden ruler to illustrate this fact. Grasp the ruler with both hands, fingers on one edge and thumbs on the opposite edge. Try to bend the ruler into 


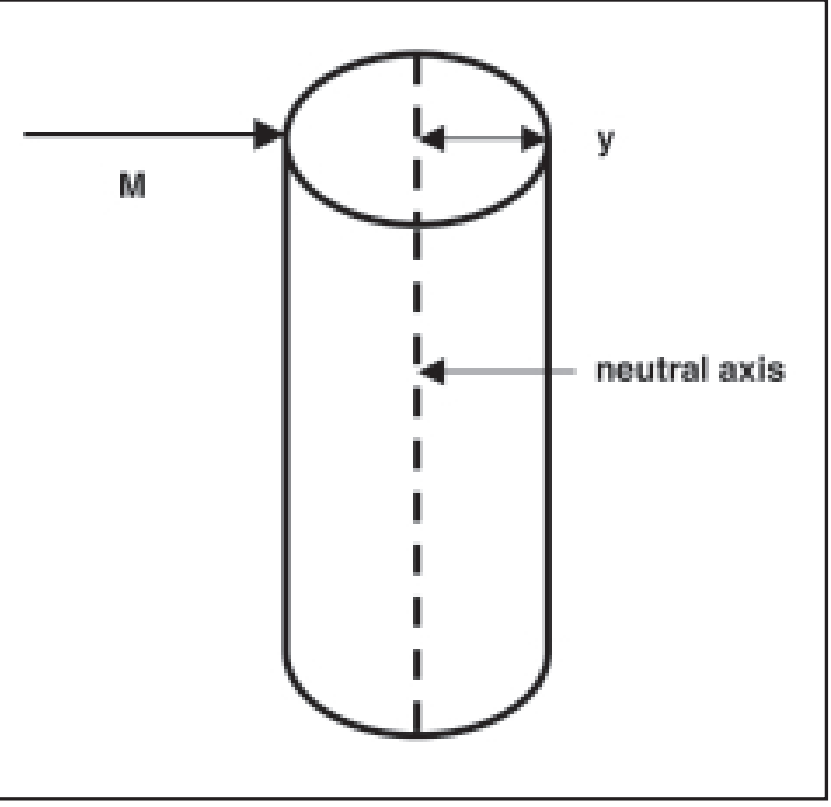

Figure 1. A beam of circular cross-section to which a bending moment $(M)$ is applied; $(y)$ is the distance between the neutral axis of bending (which is perpendicular to $M$ and shown as the dashed line) and an outside edge of the beam. In this case, $y$ equals the radius of the circle. The neutral axis is also the axis about which the moment of inertia would be calculated.

an arc by exerting a downward force with the fingers and an upward force with the thumbs; the ruler does not move much. Conversely, grasp the ruler with both hands, fingers on the top side of the ruler (side with unit markings) and thumbs on the underside. It is much easier to bend the ruler by applying a downward force with the fingers and an upward force with the thumbs.

Throughout the paper, we will refer to the axis about which $I$ is calculated; it is the axis perpendicular to the applied force that $I$ resists (in Figure 1, the neutral axis is the axis about which $I$ is calculated). It is easy to imagine a tree cross-section that is not perfectly circular; for such a tree, $I_{\text {STEM }}$ would be different depending on the direction in which a force acted (for further explanation, see Appendix 1).

When decay is present, $I_{\text {STEM }}$ is reduced and the degree to which it is reduced depends on the size and location of the decay area. Larger areas of decay reduce $I_{\text {STEM }}$ exponentially more than smaller areas of decay. When decay occurs off-center in the stem cross-section, $I_{\text {STEM }}$ is also reduced exponentially, even if the area of decay remains the same. This is so because the outer wood fibers are removed. For the same reason, cavities also reduce $I_{\text {STEM }}$ exponentially. We explain these concepts in more detail in Appendices 1 and 2. For the derivation of I and its significance to beam mechanics, refer to Niklas (1992), or Beer and Johnston (1988).
Three of the strength loss formulas (Wagener 1963; Coder 1989; Smiley and Fraedrich 1992) actually estimate the percent loss in $I_{\text {STEM }}$ due to decay (Kane et al. 2001). This is an important clarification, because in assessing the probability of failure, the formulas do not consider the force acting on the tree nor do they consider the tree's wood strength. They only consider the amount of decay and stem diameter to estimate the percent loss in $I_{\text {STEM }}$ and use that percentage to assess the probability of failure. Wagener's (1963) and Coder's (1989) formulas, however, do not account for off-center decay areas or cavities on the trunk. Instead, their formulas estimate the tree cross-section and decay areas as concentric circles, like a pipe. The Smiley and Fraedrich (1992) formula also approximates the tree crosssection and decay areas as concentric circles, and it accounts for trunk cavities. Fraedrich (1999) created a table of sound wood thicknesses based on the Smiley and Fraedrich (1992) formula. To avoid confusion, we will refer only to the Smiley and Fraedrich (1992) formula in this paper. Because the formulas consider trunk cross-sections and decay areas to be concentric circles, they may not accurately reflect the actual loss in $I_{\text {STEM }}$.

Mattheck and Breloer's (1998) formula is based on the buckling strength of a cylinder. Developed by examining failed and standing trees with decay, it is an empirically based threshold [i.e., the ratio of sound wood thickness $(t)$ to tree radius $(R), t / R]$. The $t / R$ ratio does not give loss in $I_{\text {STEM }}$ values; it only presents the threshold at which remedial action (like removal or crown reduction) should occur. Although this approach accounts for off-center decay areas, it is not directly comparable with the loss in $I_{\text {STEM }}$. Mattheck and Breloer's (1998) formula considers cavities less than one-third of the stem circumference having no effect on failure.

Each formula also has an associated threshold for action, either percent loss in $I_{\text {STEM }}$ (Wagener 1963; Coder 1989; Smiley and Fraedrich 1992) or sound wood thickness (Mattheck and Breloer 1998). In other words, when the formula returns either a percent loss in $I_{\text {STEM }}$ or a $t / R$ value that exceeds the threshold, the risk of failure merits some type of remediation. Each formula's threshold assumes that the only stem defect is decay, and that no complicating factors exist. Wagener's (1963) threshold is 33\% loss in $I_{\text {STEM }}$. Values greater than $33 \%$ loss in $I_{\text {STEM }}$ imply that the tree should be classified a hazard. Coder (1989) proposed two thresholds; between $20 \%$ and $44 \%$ loss in $I_{\text {STEM }}$, the tree is classified in the "caution" zone; with greater than 44\% loss in $I_{\text {STEM }}$, the tree is classified a hazard. Smiley and Fraedrich (1992) also use 33\% loss in $I_{\text {STEM }}$ for a threshold. Mattheck and Breloer (1998) consider cross-sections with $t / R<0.3 \mathrm{a}$ hazard. Table 1 summarizes the thresholds.

To test the accuracy of each formula's estimates for loss in $I_{\text {STEM }}$, we compared each formula's estimates to the actual 
Table 1. Each formula's threshold(s) for taking action to remedy a hazard tree.

\begin{tabular}{lllll}
\hline & Wagener & Coder & Smiley and Fraedrich & Mattheck and Breloer \\
\hline $\begin{array}{l}\text { Hazard } \\
\text { threshold }\end{array}$ & $33 \%$ loss in I & $\begin{array}{l}20 \% \leq \text { loss in } I \leq 44 \%=\text { caution } \\
>44 \% \text { loss in } I=\text { hazard }\end{array}$ & $33 \%$ loss in I & t/R $<0.3$ \\
\hline
\end{tabular}

maximum loss in $I_{\text {STEM }}$ for trees with cavities and decay. We calculated the actual loss in $I_{\text {STEM }}$ by applying the parallel axis theorem to the trees. Although the parallel axis theorem gives the actual loss in $I_{\text {STEM }}$, it cannot be readily applied in practice because its use requires a clear view of the stem cross-section (e.g., Figures 2 and 3). For a detailed treatment of the parallel axis theorem, see Appendix 2 or Beer and Johnston (1988).

\section{MATERIALS AND METHODS}

To compare the formulas' estimates for loss in $I_{\text {STEM }}$ to the actual loss in $I_{\text {STEM }}$, we examined 19 trees with cavities and decay [described in Kane and Ryan (2003)] and photographed a cross-section from each. We printed each photograph, measured sound wood thickness at several locations on each cross-section, and averaged them as described by Fraedrich (1999). We multiplied the average sound wood thickness for each stem by two and subtracted it from the stem diameter to obtain an approximate hollow diameter. We entered the tree and decay column diameters for each cross-section into the Wagener (1963), Coder (1989), and Smiley and Fraedrich (1992) formulas to determine each formula's estimate for percent loss in $I_{\text {STEM }}$.

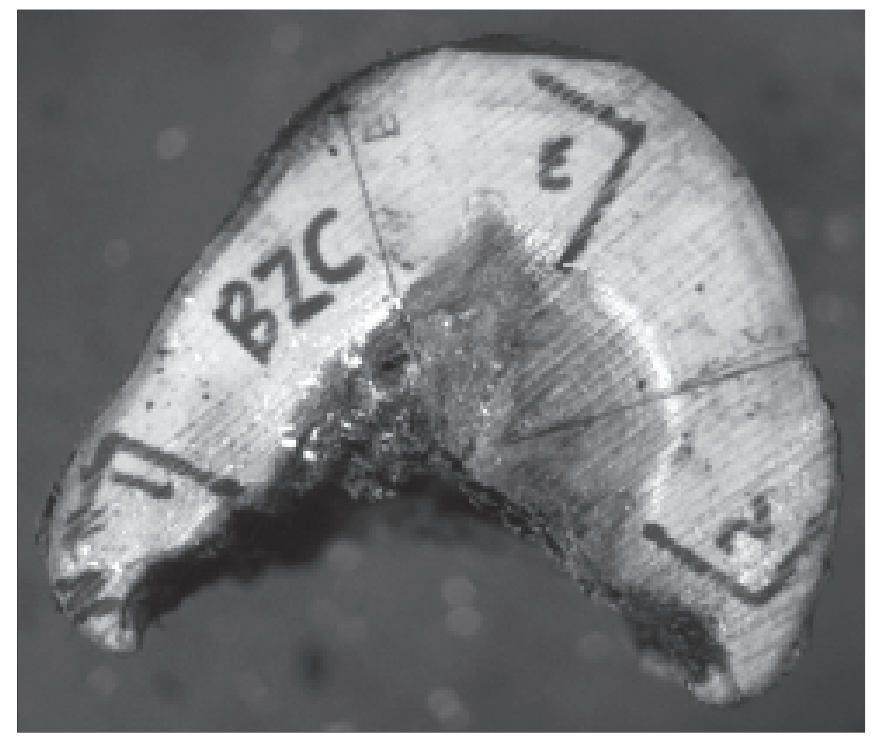

Figure 2. A typical tree underestimated by the strength loss formulas (i.e., each formula's estimate for loss in $I_{\text {STEM }}$ did not consider that formula's threshold even though the actual loss in $I_{\mathrm{MAX}}$ exceeded each formula's threshold). Mattheck and Breloer's (1998) $t / R$ ratio did not underestimate this tree.
From each photograph, we calculated the actual percent loss in $I_{\text {STEM }}$ about two or three different axes through the cross-section using the parallel axis theorem. For each stem, we calculated the loss in $I_{\text {STEM }}$ about the north-south $\left(I_{\mathrm{NS}}\right)$ and east-west $\left(I_{\mathrm{EW}}\right)$ centroidal axes. A centroidal axis is one that passes through the centroid or geometric center of the cross-section. We chose north-south and east-west centroidal axes because they were easily and repeatedly measured dimensions for each stem section and to compare the effect of decay position on loss in $I_{\text {STEM }}$. If it were visually apparent from the photograph that the actual maximum loss in $I_{\text {STEM }}$ (we will refer to it as loss in $I_{\text {MAX }}$ from now on) did not correspond to the loss in either $I_{\mathrm{NS}}$ or $I_{\mathrm{EW}}$, we chose the axis about which loss in $I_{\text {MAX }}$ would occur and calculated it using that axis (see Figure 6 in Appendix 3). In Appendix 3 we explain in more detail how we used the parallel axis theorem to calculate loss in $I_{\mathrm{NS}}, I_{\mathrm{EW}}$, and $I_{\mathrm{MAX}}$.

We tested for significant differences between each formula's (Wagener 1963; Coder 1989; and Smiley and Fraedrich 1992) loss in $I_{\text {STEM }}$ estimate and the actual loss in $I_{\text {MAX }}$ using Wilcoxon's signed rank test for paired data



Figure 3. A typical tree overestimated by using the $t / R$ ratio (i.e., $t / R<0.3$, but the actual loss in $I_{M A X}<33 \%$ ). Mattheck and Breloer (1998) noted that when $t / R=0.3$, loss in $I_{\text {STEM }} \approx 33 \%$. 
(Mendenhall and Reinmuth 1982). For each of the sample stem cross-sections, we also assessed whether each formula's estimate of loss in $I_{\text {STEM }}$ exceeded the action threshold of the formula and whether the actual loss in $I_{\text {MAX }}$ value exceeded each formula's threshold. To compare whether actual loss in $I_{\text {MAX }}$ values differed from Mattheck and Breloer's (1998) threshold, we used the thinnest remaining wall on each stem to compute the $t / R$ ratio. When $t / R=0.3$, loss in $I_{\text {STEM }}$ equals approximately 33\% (Mattheck and Breloer 1998), so we used $33 \%$ as the threshold to compare the $t / R$ values to the actual loss in $I_{\text {MAX }}$ values.

If a formula's estimate for loss in $I_{\text {STEM }}$ did not exceed that formula's threshold, but the actual loss in $I_{\mathrm{MAX}}$ did exceed the threshold used with the formula, we considered the discrepancy an "underestimate." Conversely, an "overestimate" occurred when a formula's estimate for loss in $I_{\text {STEM }}$ exceeded that formula's threshold, but the actual loss in $I_{\text {MAX }}$ did not exceed the threshold used with the formula. For each formula, we present the number (under- or overestimates) between each formula and the actual loss in $I_{\mathrm{MAx}}$.

Because of the threshold nature of the formulas' loss in $I_{\text {STEM }}$ calculations, small variations in the results become important. For example, if the actual loss in $I_{\mathrm{MAX}}$ were $35 \%$, the tree would be considered a hazard because it exceeded the 33\% threshold. Yet, if one of the formulas determined the loss in $I_{\text {STEM }}$ to be $29 \%$, the tree would be considered "safe" (i.e., below the threshold). The loss in $I_{\text {STEM }}$ values (29\% and 35\%) might not be statistically different, but they are different as far as determining whether an arborist would recommend remedial action for the tree. This is an important distinction because an arborist or urban forester must be aware of both a formula's overall accuracy and its potential to misclassify a tree as a hazard.

\section{RESULTS AND DISCUSSION}

The decay present in most of the trunk sections did not occur in concentric circles. Rather, areas of decay, distinguished by discolored wood and hollows, were irregular in shape and offset from the center of the stem (see Figures 2 and 3 , for example). In addition, none of the cavity openings exceeded 33\% of stem circumference, which is Mattheck and Breloer's (1998) threshold for considering a tree hazardous based on the cavity opening alone. Table 2 summarizes our results.

Although there were no significant differences between loss in $I_{\mathrm{NS}}$ and loss in $I_{\mathrm{EW}}$, significant differences occurred between loss in $I_{\mathrm{MAX}}$ and the smaller of loss in $I_{\mathrm{NS}}$ and loss in $I_{\mathrm{EW}}$. The mean difference was $9.3 \%$ loss in $I_{\text {STEM }}$. This was due to the presence of off-center decay areas and cavities in the stems. When off-center decay and cavities occurred, loss in $I_{\text {STEM }}$ varied because the value of $I_{\text {STEM }}$ depends on the axis about which it is calculated (unless the stem cross-section is symmetrical) and the cross-sectional position of decay. It is also notable that large differences among the formulas' estimates of loss in $I_{\text {STEM }}$ and the actual loss in $I_{\text {MAX }}$ values only occurred on trees where the disparity between loss in $I_{\mathrm{MAX}}$ and the smaller of loss in $I_{\mathrm{NS}}$ or loss in $I_{\mathrm{EW}}$ exceeded $10 \%$ (7 of 19 trees). Such trees had decay areas offset far from the center of the stem.

\section{Accuracy of Formula Estimates of Loss in $\boldsymbol{I}_{\text {STEM }}$ Wagener's (1963) formula returned significantly lower values of loss in $I_{\text {STEM }}$ than the actual loss in $I_{\text {MAX }}$ (mean value was 9.6\% lower). Coder's (1989) formula also returned significantly lower values of loss in $I_{\text {STEM }}$ than the actual loss in $I_{\text {MAX }}$ (mean value was $15.1 \%$ lower). Smiley and Fraedrich's (1992) formula did not return significantly}

Table 2. Comparison among formula estimates of loss in $I_{\mathrm{STEM}}$ and actual values of loss in $I_{\mathrm{MAX}}$ for 19 trees. Loss in $I_{\mathrm{MIN}}$ refers to the smaller of loss in $I_{\mathrm{EW}}$ or $I_{\mathrm{NS}}$. We calculated the mean difference by subtracting the actual loss in $I_{\text {MAX }}$ value from the formula estimate of loss in $I_{\text {STEM }}$. Threshold underestimates refers to the number of trees for which the formula's estimate for loss in $I_{\text {STEM }}$ did not exceed the formula's action threshold but the actual loss in $I_{\text {MAX }}$ did exceed the formula's action threshold. Threshold overestimates refers to the number of trees for which the formula's estimate for loss in $I_{\text {STEM }}$ exceeded the formula's action threshold but the actual loss in $I_{\text {MAX }}$ did not exceed the formula's action threshold.

\begin{tabular}{|c|c|c|c|c|c|}
\hline & Loss in $I_{\mathrm{MIN}}$ & Wagener & Coder & $\begin{array}{l}\text { Smiley and } \\
\text { Fraedrich }\end{array}$ & $\begin{array}{l}\text { Mattheck and } \\
\text { Breloer }\end{array}$ \\
\hline $\begin{array}{l}\text { Mean difference with } \\
\text { actual loss in } I_{\mathrm{MAX}}\end{array}$ & $9.3 \%^{* *}$ & $-9.6 \% *$ & $-15.1 \%^{* *}$ & $-0.5 \%$ ns & $\mathrm{n} / \mathrm{a}$ \\
\hline Standard error & 0.020 & 0.035 & 0.032 & 0.026 & $\mathrm{n} / \mathrm{a}$ \\
\hline$P$-value & $<0.0001$ & 0.0263 & $<0.0001$ & 0.9193 & $\mathrm{n} / \mathrm{a}$ \\
\hline Threshold underestimates & $\mathrm{n} / \mathrm{a}$ & 3 & 8 & 3 & 0 \\
\hline Threshold overestimates & $\mathrm{n} / \mathrm{a}$ & 0 & 0 & 1 & 3 \\
\hline
\end{tabular}


different values for loss in $I_{\text {STEM }}$ than the actual loss in $I_{\text {MAX }}$ values (mean value was $0.5 \%$ lower). It is not surprising that Wagener's (1963) and Coder's (1989) formulas returned significantly lower loss in $I_{\text {STEM }}$ values for the trees because neither formula incorporates a calculation for trunk cavities, and both consider decay areas as concentric circles. Because their formula accounts for trunk cavities, Smiley and Fraedrich's (1992) estimates for loss in $I_{\text {STEM }}$ do not differ significantly from the actual loss in $I_{\mathrm{MAX}}$.

\section{Formula Thresholds}

Wagener's (1963) formula resulted in underestimates for 3 of 19 trees (16\%) using the 33\% threshold. Using Coder's (1989) caution threshold resulted in underestimates for 8 out of 19 trees (42\%). Smiley and Fraedrich's (1992) formula misclassified 4 out of 19 trees (21\%) using the 33\% threshold; 3 trees were underestimates, 1 was an overestimate. Mattheck and Breloer's (1998) t/R ratio overestimated 3 out of 19 trees (16\%). Three of the formulas (Wagener 1963, Coder 1989, and Smiley and Fraedrich 1992) consistently underestimated trees with cross-sections resembling the one shown in Figure 2. It has a large circular sector of decay and a cavity; it also has a relatively even thickness of remaining sound wood. Because the remaining sound wood is relatively thick (average thickness was 30\% of stem diameter), the stem fell below those formulas' action thresholds and incorrectly appeared "safe."

It is noteworthy that while Wagener's (1963) formula was significantly less accurate in estimating loss in $I_{\text {STEM }}$ than Smiley and Fraedrich's (1992) formula, both of the formulas underestimated the same number of trees. These formulas differ only in that the latter accounts for cavities, and that factor was responsible for the lack of significant differences between Smiley and Fraedrich's (1992) estimates for loss in $I_{\text {STEM }}$ and the actual loss in $I_{\text {MAX }}$. However, the fact that the formulas produced the same number of underestimates even though one was significantly less accurate in estimating the loss in $I_{\text {STEM }}$ supports the notion that the formulas must be used as only one of several tools in tree risk assessment.

Mattheck and Breloer's (1998) t/R ratio overestimated more trees than the other formulas. Using this formula produced overestimates in trees with relatively small decay areas that were offset far from the center of the stem, creating a very thin remaining wall (Figure 3 ). The $t / R$ ratio did not underestimate any trees, which appears to justify Mattheck and Breloer's (1998) contention that cavity openings less than $33 \%$ of stem circumference do not significantly contribute to loss in $I_{\text {STEM }}$. We should point out, however, that the trees with the largest cavities also had enough decay to create a thin remaining wall of sound wood on the stem. In contrast, the formula might underestimate risk for trees with cavities approaching 33\% of stem circumference and thick remaining sound wood. Two of the trees we examined had cavity openings approximately 22\% of stem circumference and thick remaining walls; the $t / R$ ratio almost underestimated those trees.

Interestingly, in spite of the high losses in $I_{\text {STEM }}$ for several trees, none of them appeared to be in immediate danger of failure [using visual tree assessment techniques described by Mattheck and Breloer (1998)]. This may be due, in part, to the fact that the trees were growing in woodlots and had branching structures more typical of forest trees than opengrown trees. Furthermore, the trees received some protection from adjacent trees against wind and excessive swaying. The fact that apparently hazard trees remained standing supports the claim that the load a tree endures is critical to evaluating its risk of failure (Wessolly 1995). It also highlights the need for more studies to determine the threshold loss in $I_{\text {MAX }}$ likely to cause tree failure.

\section{CONCLUSIONS}

If the cross-section of a tree with decay resembles a hollow pipe, any of the formulas will provide a reasonable estimate for loss in $I_{\text {STEM }}$. The arborist must then assess other factors (see Matheny and Clark 1994) to determine tree risk. When cavities or off-center decay areas are present, either the Smiley and Fraedrich (1992) or Mattheck and Breloer (1998) formulas should be used. When a tree cross-section has a large cavity ( $>20 \%$ stem circumference), a deep wedge of decay, and a relatively thick wall of sound wood (Figure 2), Smiley and Fraedrich's (1992) formula may underestimate the actual loss in $I_{\mathrm{MAX}}$ and should be used with caution. When a tree cross-section has a small area of decay $(<20 \%$ of stem area) located far from the center of the stem (Figure 3), Mattheck and Breloer's (1998) formula may overestimate the actual loss in $I_{\text {MAX }}$, which should be considered in assessing probability of failure. Analysis of more stem cross-sections will help refine these guidelines.

Because serious liability could result if a tree failure damaged property or injured a person, overestimating tree risk is safer than underestimating it. However, trees provide many benefits and larger trees provide greater benefits than smaller trees (McPherson 2003). Thus, preserving large, mature trees should be a goal of arborists and urban foresters. Honing tree risk assessment skills may prolong the useful lives of mature landscape trees. In light of our findings that red maple woundwood is stronger than normal wood (Kane and Ryan 2003), our results in this paper suggest that tree risk assessment deserves considerable research attention in order to understand the tree failure process better.

\section{LITERATURE CITED}

Beer, F.P., and E.R. Johnston, Jr. 1988. Vector Mechanics for Engineers: Static (5th ed.). McGraw-Hill, New York, NY. $472 \mathrm{pp}$.

Coder, K.D. 1989. Should you or shouldn't you fill tree hollows? Grounds Maintenance 24(9):68-70, 98-100. 
Fraedrich, B.R. 1999. Guidelines for Quantifying and Evaluating Wood Decay in Stems and Branches. Bartlett Tree Research Laboratories Technical Report. Charlotte, NC. 4 pp.

Kane, B.C.P., and H.D.P. Ryan. 2003. Examining formulas that assess strength loss due to decay in trees: Woundwood toughness improvement in red maple (Acer rubrum). J. Arboric. 29(4):208-215.

Kane, B., D. Ryan, and D.V. Bloniarz. 2001. Comparing formulae that assess strength loss due to decay in trees. J. Arboric. 27(2):78-87.

Mattheck, C., and H. Breloer. 1998. The Body Language of Trees. The Stationery Office. London, England. 240 pp.

McPherson, E.G. 2003. A benefit-cost analysis of ten street tree species in Modesto, California, U.S. J. Arboric. 29(1):1-8.

Mendenhall, W., and J.E. Reinmuth. 1982. Statistics for Management and Economics (4th ed.). PWS Publishers, Boston, MA. 902 pp.

Niklas, K.J. 1992. Plant Biomechanics: An Engineering Approach to Plant Form and Function. University of Chicago Press, Chicago, IL. 607 pp.

Smiley, E.T., and B.R. Fraedrich. 1992. Determining strength loss from decay. J. Arboric. 18(4):201-204.

Wagener, W.W. 1963. Judging Hazards from Native Trees in California Recreational Areas: A Guide for Professional Foresters. USFS Research Paper PSW-P1, 29 pp.

Wessolly, L. 1995. Fracture diagnosis of trees-Part 1: Statics-Integrated Methods-measurement with tension test. Stadt und Grün 6:416-422.

Acknowledgments. This research was supported in part by the State Farm Insurance Companies Foundation and by a TREE Fund John Z. Duling Grant. We would like to thank Jim Clark, Susan Day, E. Thomas Smiley, and an anonymous reviewer for offering helpful suggestions on earlier drafts of the manuscript.

${ }^{1 * A s s i s t a n t ~ P r o f e s s o r ~ o f ~ C o m m e r c i a l ~ A r b o r i c u l t u r e ~}$ University of Massachusetts

Amherst, MA 01003, U.S.

bkane@forwild.umass.edu

${ }^{2}$ Professor of Arboriculture and Urban Forestry

University of Massachusetts

Holdsworth Hall

Amherst, MA 01003, U.S.

*Corresponding author.

\section{APPENDIX 1}

Essentially, the moment of inertia of a tree stem $\left(I_{\text {STEM }}\right)$ reflects its resistance to bending. It is based on the shape of the stem cross-section and is calculated as the summation over the entire stem cross-sectional area $(A)$ of each increment of stem cross-sectional area $(d A)$ multiplied by the square of the distance $(y)$ between the increment of area $d A$ and the centroid (or geometric center) of the stem:

$$
\int_{A} y^{2} d A
$$

From Equation Al, it is clear that to calculate I, one considers only cross-sectional geometry; material properties (e.g., wood strength) are irrelevant. Thus, one calculates I the same way for a steel beam as for a tree stem. The only difference is that as trees add girth each year, $I_{\text {STEM }}$ will change because $A$ and $y$ will change in Equation Al) It is also clear from Equation Al that I increases exponentially as the distance $y$ from the centroid to an increment of area increases.

When decay is present, $I_{\text {STEM }}$ decreases because there is less wood to resist a bending force. The percent loss in $I_{\text {STEM }}$ due to decay can be calculated by dividing I of the decayed area $\left(I_{\text {DECAY }}\right)$ by $I_{\text {STEM }}$ :

$$
\% \text { loss in } I_{\text {STEM }}=\frac{I_{\text {DECAY }}}{I_{\text {STEM }}}
$$

Equation $\mathrm{A} 2$ is the procedure that three of the formulas (Wagener 1963; Coder 1989; Smiley and Fraedrich 1992) use to estimate strength loss, which is actually an estimate of loss in $I_{\text {STEM }}$. In Equation A2, we need to calculate two separate values of $I$, one for the stem cross-sectional area assuming no decay is present $\left(I_{\text {STEM }}\right)$, and one for the decay area. To calculate $I_{\mathrm{DECAY}}$, we again use Equation $\mathrm{Al}$, but this time $A$ represents the decay area and $y$ represents the distance between an increment of the decay area and the centroid of the decay area.

Unless the stem cross-section is symmetrical, the axis about which one calculates $I_{\text {STEM }}$ will affect its value (recall the ruler analogy earlier in this article). Consider two crosssections-a circle and an ellipse (Figure 4). For the circle, I is constant regardless of the axis about which it is calculated, as long as the axis passes through the centroid (this is called a centroidal axis). For the ellipse, I depends on the centroidal axis about which it is calculated because the axes are not equal in length. In Figure 4,

$$
\begin{gathered}
I_{\text {CIRCLE }}=\pi R^{4} / 4 \\
I_{\text {ELIPSE }} \text { about the XX' axis }=\pi a^{3} b / 4 \\
I_{\text {ELLPSE }} \text { about the } \mathrm{YY}^{\prime} \text { axis }=\pi a b^{3} / 4
\end{gathered}
$$




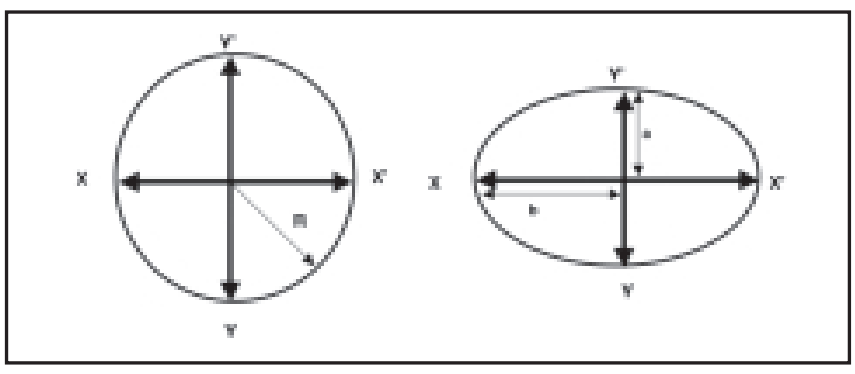

Figure 4. Centroidal moment of inertia (I) of a circle is the same regardless of the centroidal axis about which $I$ is calculated, because the circle is symmetrical about any centroidal axis: $I_{\mathrm{XX}^{\prime}}=I_{\mathrm{YY}^{\prime}}=\pi R^{4} / 4$. Centroidal moment of inertia ( $I$ ) of an ellipse varies as a function of the centroidal axis about which $I$ is calculated: $I_{\mathrm{xx}^{\prime}}=$ $\pi a^{3} b / 4 ; I_{Y^{\prime}}=\pi a b^{3} / 4$. Centroids for the circle and ellipse occur where the $X X^{\prime}$ and $Y Y^{\prime}$ axes intersect.

where the notation is explained in Figure $4(\pi \approx 3.14)$. In Figure 4, only two centroidal axes are shown (XX' and $\left.Y^{\prime}\right)$, but remember that I can be calculated about any centroidal axis. Figures 4 and 5 (Figure 5 is explained in Appendix 2) show that $I_{\text {STEM }}$ depends on (1) the direction in which a force acts on the tree, if its cross-section is asymmetric; (2) the stem cross-sectional shape; and (3) the cross-sectional shape and position of decay in the stem. For the ellipse in Figure 4, if we imagine a force acting perpendicular to the $Y^{\prime}$ axis, the resistance to that force will be much greater than if the force acted perpendicular to the XX' axis.

\section{APPENDIX 2}

We can most easily explain how to apply the parallel axis theorem for calculating $I_{\text {STEM }}$ with an example. Consider two circular trunk cross-sections (Figure 5), one with a concentric circle of decay and one with an off-center circle of decay. In the former case, the decay and the stem crosssection share the same centroid of area. Therefore (from Equations A2 and A3),

$$
\% \text { loss in } I_{\text {STEM }}=\frac{\pi^{*} R_{I}^{4} / 4}{\pi^{*} R_{O}^{4} / 4}
$$

where $R_{O}$ is the tree radius and $R_{I}$ is the radius of the decay. The units for I cancel in Equation A6, leaving just the percent loss in $I_{\text {STEM }}$. For the situation with off-center decay, we must account for the fact that the decay and tree crosssections, even though they are both circles, do not share the same centroid of area. We still use Equation A2, but we need to find $I_{D E C A Y}$ about the stem's centroidal axis (shown as a dashed line in Figure 5) rather than the centroidal axis of the decay area (shown as a solid line in the right cross-section in Figure 5). To do this, we apply the parallel axis theorem, which states that $I_{D E C A Y}$ about the stem's centroidal axis equals

$$
I_{\mathrm{DECAY}}+A_{\mathrm{DECAY}} * d^{2}
$$

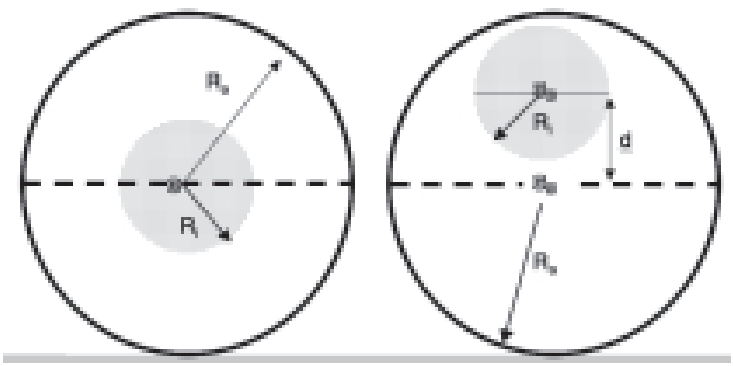

Figure 5. Two circular cross-sections representing stems. On the left, decay area (shaded circle) is a concentric circle; on the right, decay is circular but off-center. For the cross-section on the left, $C$ is the shared centroid of the stem and decay areas. For the cross-section on the right, $C_{D}$ is the centroid of the decay area, $C_{S}$ is the centroid of the stem, and $d$ is the distance between the centroids of the stem and decay areas. In each crosssection, $R_{I}$ is the radius of the decay area and $R_{0}$ is the radius of the stem. The parallel axis theorem accounts for off-center decay areas when calculating loss in $I_{\text {STEM }}$.

where $I_{D E C A Y}$ is I of the decay area about its own centroidal axis, $\left(A_{\mathrm{DECAY}}\right)$ is the area of decay (for a circle, $A_{\mathrm{DECAY}}=\pi * R_{I}^{2}$ ) and $(d)$ is the distance between the centroid of the stem cross-section and the centroid of the decay cross-section. Now, when decay is present in the stem, from Equations A2, A3, and A7, we have

$$
\% \text { loss in } I_{\text {STEM }}=\frac{\pi * R_{I}^{4} / 4+\pi * R_{1}^{2} * d^{2}}{\pi * R_{0}^{4} / 4}
$$

Note that when decay is present, the percent loss in $I_{\text {STEM }}$ increases exponentially the farther the decay is from the centroid of the stem cross-section. When the decay and stem cross-sectional areas share the same centroid, $d=0$, so Equation A8 reduces to Equation A6.

\section{APPENDIX 3}

We used the parallel axis theorem to calculate loss in $I_{\text {STEM }}$ for the sample sections as follows. First, we took a $35 \mathrm{~mm}$ slide of each trunk cross-section. We scanned the slides, printed the images, traced the prints onto cardboard and trimmed the cardboard, leaving a scaled cardboard replica of the original cross-section. We used the cardboard cutouts to determine the centroid of the stem cross-sections using the method described by Niklas (1992, p. 135). The method uses the fact that, for homogeneous materials, the centroid of an area corresponds to its center of mass. Although wood from tree cross-sections is not homogeneous, differences in density are small enough that it is safe to approximate the centroid as the center of mass. We determined two centroids 
for each tree cross-section, one assuming that decay and hollow areas were absent $\left(\mathrm{C}_{\mathrm{S}}\right)$ and a second assuming decay and hollow areas were present $\left(\mathrm{C}_{\mathrm{H}}\right)$. We assumed that the mass of any decayed or discolored wood was insignificant, and eliminated it from the cardboard cutouts when determining $\mathrm{C}_{\mathrm{H}}$. We transferred $\mathrm{C}_{\mathrm{H}}$ and $\mathrm{C}_{\mathrm{S}}$ for each stem cross-section from the cardboard cutouts to the printed images. The $\mathrm{C}_{\mathrm{S}}$ was on one printed image and the $\mathrm{C}_{\mathrm{H}}$ on a second.

On each image, we drew north-south (NS) and eastwest (EW) axes through the centroid as well as lines parallel to each axis at $6.35 \mathrm{~mm}$ (0.3 in.) intervals. If it were visually apparent that calculating loss in $I_{\mathrm{NS}}$ and loss in $I_{\mathrm{EW}}$ would not produce the loss in $I_{\mathrm{MAX}}$, we calculated an additional value for loss in $I_{\text {STEM }}$ about the centroidal axis that returned the loss in $I_{\mathrm{MAX}}$ for that stem section. When looking at a cross-

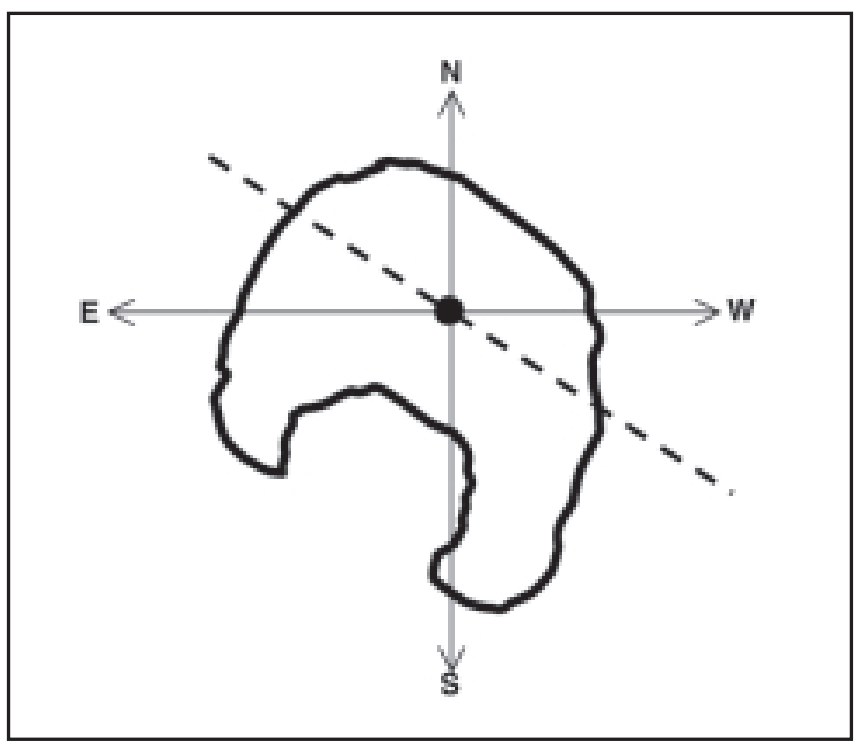

Figure 6. For a roughly circular cross-section, the maximum loss in $I_{\text {STEM }}\left(I_{M A X}\right)$ will occur about the centroidal axis parallel to a cavity opening (shown as a dashed line). The dot represents the centroid of the cross-section and the north-south (NS) and east-west (EW) centroidal axes are shown as thin lines with arrowheads. For a cross-section similar to that shown here, we calculated loss in $I_{\text {STEM }}$ about the NS and EW centroidal axes, and loss in $I_{M A X}$ because neither loss in $I_{\text {STEM }}$ about the NS centroidal axis nor loss in $I_{\text {STEM }}$ about the EW centroidal axis represented the actual loss in $I_{\mathrm{MAX}}$. section, it is not hard to determine which centroidal axis will return the loss in $I_{\mathrm{MAX}}$ because the outer fibers of the stem cross-section contribute exponentially more to $I_{\text {STEM }}$. On cross-sections with large cavities, for example, the loss in $I_{\text {MAX }}$ would occur about the centroidal axis parallel to the widest part of the cavity (Figure 6).

Figure 7 shows a cross-section with the NS axis (dashed black line) through the centroid (large white dot) and lines parallel to the axis creating rectangles. The small white dots in the middle of each rectangle represent their centroids $\left(C_{R}\right)$. We measured the length of each line, took the average of two adjacent lines (e.g., $\mathrm{L}_{\mathrm{i}}$ and $\mathrm{L}_{\mathrm{i}+1}$ ), and multiplied the average by $6.35 \mathrm{~mm}$ to estimate the area $(A)$ of each rectangle:

$$
A=\frac{\left(L_{i}+L_{i+1}\right)}{2} * 6.35
$$

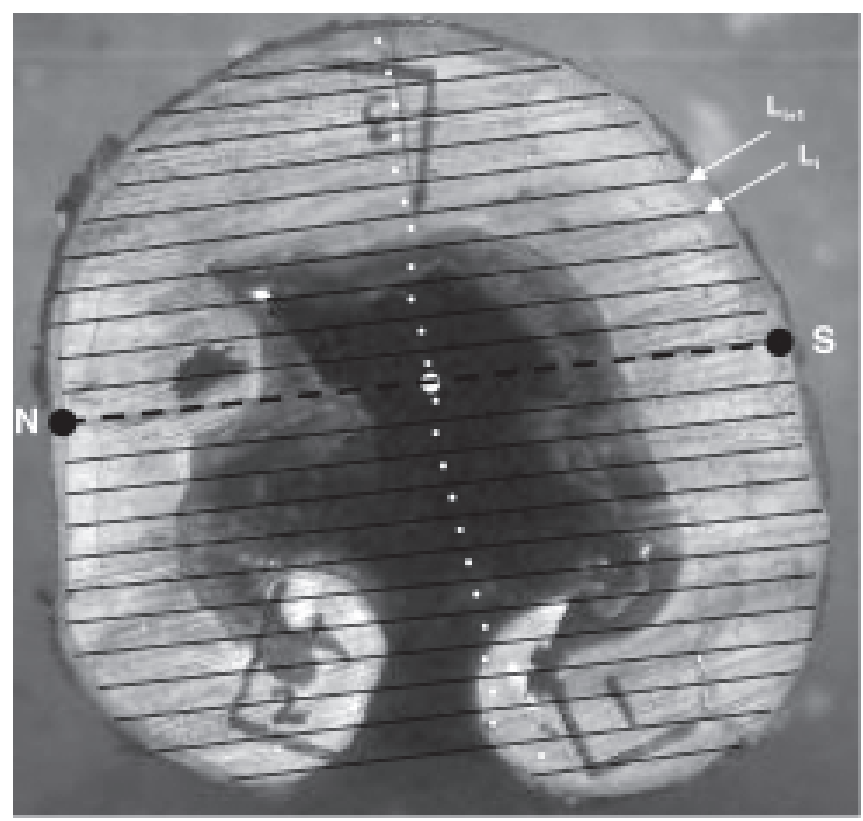

Figure 7. Diagram illustrating how we used the parallel axis theorem to calculate loss in I for tree crosssections. The cross-section shows the north-south (NS) centroidal axis (dashed black line) through the centroid of the cross-section (large white dot) and lines parallel to it (solid black). Small white dots indicate centroids of each rectangle. See the text for details of the calculation procedure. 
We divided all distance measurements (e.g., $\mathrm{L}_{\mathrm{i}}, \mathrm{L}_{\mathrm{i}+1}$, and 6.35) by the image scale (IS) before calculating $A$ and $I$ of each rectangle.

To calculate $I_{\text {NS }}$ we used the parallel axis theorem and summed I of each rectangle about the NS centroidal axis:

$$
I_{\mathrm{NS}}=\sum_{i=1}^{n} I_{i}+A_{i} * d_{i}^{2}
$$

where $(n)$ is the number of rectangles parallel to the NS centroidal axis and $(i)$ represents a given rectangle. Equation A9 gives the area for each rectangle $\left(A_{i}\right),\left(d_{i}\right)$ is the measured distance between $C_{S}$ and $C_{R}$, and $I$ for each rectangle $\left(I_{i}\right)$ is calculated

$$
I_{i}=\frac{\left[\left(L_{i}+L_{i+1} / 2\right)\right] / \text { IS } *(6.35 / \text { IS })^{3}}{12}
$$

We calculated $I_{\mathrm{NS}}$ assuming the trunk sections had no decay, and then we calculated $I_{\text {DECAY }}$ about the NS centroidal axis $\left(I_{\text {DECAY NS }}\right)$ using the same procedures (Equations A9, $A 10$, and A11). To calculate $I_{\text {DECAY NS }}$, we summed the rectangles that covered decay areas and used $\mathrm{C}_{\mathrm{H}}$. Using Equation A6, we calculated the percent loss in $I_{\mathrm{NS}}$ due to decay. We repeated the above procedures (Equations A9, $\mathrm{A10}, \mathrm{Al1}$, and A6) for the EW centroidal axis, and, if necessary, for the centroidal axis that produced the loss in $I_{\mathrm{MAX}}$. For each trunk cross-section, then, we calculated loss in $I_{\mathrm{NS}}\left(I_{\mathrm{DECAY} N S} / I_{\mathrm{NS}}\right)$, loss in $I_{\mathrm{EW}}\left(I_{\mathrm{DECAY} \mathrm{EW}} / I_{\mathrm{EW}}\right)$, and, if necessary, loss in $I_{\text {MAX }}$. 
Zusammenfassung. Es gibt 4 Formeln, die Arboristen in den Vereinigten Staaten oft nutzen, um die Wahrscheinlichkeit eines Baumversagens zu untersuchen. Obwohl sie gewöhnlich als die „Kraftverlustformeln” zitiert werden, schätzen drei der Formeln den Verlust in Stem moment of inertia $\left(\mathrm{I}_{\text {STEM }}\right)$ um die Wahrscheinlichkeit des Baumversagens zu bewerten. Die Formeln. Schätzen den Verlust in $\mathrm{I}_{\text {STEM }}$ Indem sie den Stamm und die Fäulnisstellen als Querschnitt in konzentrischen Kreisen modellieren. Für viele Bäume mit Fäule gilt dennoch, dass weder der Stamm noch die

Fäulnisstellen im Querschnitt konzentrische Kreise ergeben und das mag die Anwendung dieser Formeln limitieren. Die 4. Formel basiert auf der Stärke eines Zylinders und bietet auch die Messung des wahrscheinlichen Stammversagens. Um zu testen, wie gut diese Formeln den Verlust in $\mathrm{I}_{\text {STEM }}$ schätzen, verglichen wir jedes Formelergebnis mit dem aktuellen Verlust in $\mathrm{I}_{\text {STEM }}$, den wir mit dem Paralllel-Axis-Theorem beerchnet hatten. Obwohl das Paralllel-Axis-Theorem den aktuellen Verlust in $\mathrm{I}_{\text {STEM }}$ bestimmt, kann es dennoch nicht genutzt werden, weil ein Bild des Baumquerschnitts für die Anwendung erforderlich ist. Deutliche Unterschiede bestanden zwischen den Schätzungen zweier Formeln und dem aktuellen Wert. Jede der Formeln misklassifizierte einige Bäume bis dahin, wo der Aktionsrahmen der Formeln überschritten wurde. Als wir den aktuellen Verlust in $\mathrm{I}_{\text {STEM }}$ für diese Bäume berechneten, war es weniger als 33\%. Wir stellen hier repräsentative Stammquerschnitte aus, für welche die Formeln kein akkurates Messergebnis liefern konnten.

Resumen. Hay 4 fórmulas que los arboristas en los Estados Unidos usan para medir la probabilidad de falla de un árbol. A pesar que ellas son comúnmente referidas como "fórmulas de pérdida de resistencia" tres de las fórmulas (Wagener 1963, Coder 1989, Smiley and Fraedrich 1992) realmente estiman la pérdida en momento de inercia del tronco $\left(\mathrm{I}_{\text {STEM }}\right)$ para evaluar la probabilidad de falla. Las fórmulas estiman la pérdida en $\mathrm{I}_{\text {STEM }}$ mediante el modelamiento del tronco y áreas de sección trasversal de decaimiento como anillos concéntricos. Para muchos árboles con decaimiento, sin embargo, ni el tronco ni las secciones transversales se asemejan a anillos concéntricos y esto puede limitar la precisión de las fórmulas. La cuarta fórmula (Mattheck and Breloer 1998) basada en la resistencia al doblamiento de un cilindro, también ofrece una medida de la probabilidad de falla del tronco. Para probar qué tan bien estiman las fórmulas la pérdida en $\mathrm{I}_{\text {STEM }}$, se compararon estimadores de cada fórmula para pérdidas en $\mathrm{I}_{\text {STEM }}$ con la pérdida real en $I_{\text {STEM, }}$ que fue calculada usando el parallel axis theorem y técnicas de ingeniería. A pesar de que el parallel axis theorem proporciona las pérdidas reales en $\mathrm{I}_{\mathrm{STEM}}$, no puede ser usado en la práctica porque se requiere una imagen de la sección transversal del árbol para aplicarlo. Existieron diferencias significativas entre 2 fórmulas (Wagener 1963, Coder 1989) para estimar la pérdida en $\mathrm{I}_{\text {STEM }}$. Se presentan secciones trasversales representativas para cada una de las fórmulas que no muestran con precisión las pérdidas en $\mathrm{I}_{\text {STEM }}$.

Résumé. Il y a quatre formules que les arboriculteurs des États-Unis utilisent souvent pour évaluer la probabilité de bris pour les arbres. Même si on y réfèrent communément sous le générique «formules de perte de résistance », trois de ces formules (Wagener 1963, Coder 1989, Smiley et Fraedrich 1992) estiment actuellement la perte de moment inertiel de la tige pour évaluer la probabilité de bris. Les formules estiment cette perte en modélisant la tige et la coupe transversale de la carie comme des cercles concentriques. Pour plusieurs arbres cariés cependant, ni la tige ni la coupe transversale de la zone de carie ne ressemblent à des cercles concentriques, ce qui peut dès lors limiter la fiabilité de ces formules. La quatrième formule (Mattheck et Breloer 1998) est basée sur la force de déformation d'un cylindre; elle offre également une mesure de la probabilité du bris de la tige. Afin de tester jusqu'à quel point ces formules estiment correctement la perte en moment inertiel de la tige, nous avons comparé les estimations de chacune des formules par rapport à la perte actuelle que nous avons calculé au moyen du théorème de parallèle axial, une technique employée en ingénierie. Même si le théorème de parallèle axial donne la perte actuelle en moment inertiel de la tige, il ne peut être utilisé en pratique parce qu'une image de la section transversale de l'arbre est requise pour l'appliquer. Des différences significatives existent entre les estimés de perte en moment inertiel de la tige de deux formules (Wagener 1963, Coder 1989) et la valeur actuelle. Chacune de ces formules classent incorrectement certains arbres lorsque ces derniers se retrouvent hors du champ d'application de la formule. Cependant, lorsque nous avons calculé la perte actuelle en moment inertiel de la tige de ces arbres, elle était inférieure à $33 \%$. Nous avons également représenté certaines coupes typiques de tiges pour lesquelles les formules ne représentent pas fidèlement la perte en moment inertiel de la tige. 